\title{
An Extended Transportation Problem with Multiple Inputs and Outputs
}

\author{
${ }^{1}$ Gedam V.K and ${ }^{2}$ Mahamad B. Pathan. \\ ${ }^{I}$ Department of Statistics, Savitribai Phule Pune University, Pune, Maharashtra, India. \\ ${ }^{2}$ Department of Statistics, Poona College of Arts, Science and Commerce, Pune, Maharashtra, India.
}

\begin{abstract}
We propose an extension to the classical transportation problem by considering multiple incommensurate inputs and outputs for each shipment link. The relative efficiency concept is defined for each shipment link. Two linear programming models are used to determine the optimal transportation plan with maximum efficiency. The applicability of the approach is discussed with a numerical example.
\end{abstract}

Keywords: Transportation problem (TP). Decision making units (DMUs). Data envelopment analysis (DEA). Relative efficiency.

\section{Introduction}

The transportation problem is commonly applicable in the field of operations research. It is a subclass of linear programming problem. The main objective in transportation problem is to minimise the cost of shipping homogeneous commodity from various origins to various destinations with respective rim requirements. Only cost or profit for each possible shipment link is taken into account during the formulation of classical transportation problem.

In many real applications, several kinds of variables such as cost, distance, shipment value, manpower, profit, etc. may be involved for each possible shipment link, which are to be considered during the shipment plan. The decision makers may have different aims to achieve for each possible shipment link. In such situation, we are interested to decide an optimal transportation plan with maximum relative efficiency.

Data envelopment analysis (DEA) was firstly introduced by Charnes et al. [3] in the literature. It is a mathematical approach which assesses the comparative efficiency of a set of decision making units (DMUs) such as airlines, railways, banks, automobile manufacturers, hospitals, universities, etc.

DEA has become popular in the practise and in the research of efficiency analysis. Many developments in concepts and methodologies related to the DEA have led by Banker et al. [2] and Cooper et al. [6, 7]. The seminal paper by Charnes, Cooper and Rhodes [3], a variety of DEA models has appeared in the literature. Charnes, Cooper, and Rhodes [3] suggested a model to compute relative efficiency of various DMUs named as CCR model. Another version of DEA is suggested by Banker, Charnes, and Cooper [2] (BCC) model. The primary difference between BCC model and CCR model is the treatment of returns to scale. The evaluation of efficiency by CCR model is based on the constant returns to scale. The BCC model is more flexible and allows variable returns to scale.

The literature available on transportation problem with multiple inputs and outputs is limited. We briefly review some related literatures. Chen and Lu [5] extended the assignment problem by considering multiple inputs and outputs. Alireza Amirteimoori [1] has extended transportation problem by DEA based approach. As far as we aware, there is no work regarding our proposed approach in the literature. We extend the transportation problem by considering multiple inputs and outputs by using BCC model for each shipment link. The relative efficiency for each shipment link is defined and a shipment plan with maximum efficiency is considered as an optimal plan to the transportation problem.

This paper is organized as follows. In section 2, Banker, Charnes and Cooper [2] (BCC) model is stated. In section 3, the classical transportation model is mentioned. In section 4, we described the proposed approach. In section 5, the applicability of the proposed approach is demonstrated through a numerical example. The comparison is done with an approach suggested by Alireza Amirteimoori [1]. In sections 6, conclusions are made and tables are arranged at the end.

\section{Bcc Model}

Banker, Charnes, and Cooper [2] (BCC) model with flexible output is stated as below.

$$
\text { Maximise } \frac{u_{0}+\sum_{r=1}^{s} u_{r} y_{r o}}{\sum_{i=1}^{m} v_{i} x_{i o}}
$$


Subject to:

$$
\begin{array}{ll}
\frac{u_{0}+\sum_{r=1}^{s} u_{r} y_{r j}}{\sum_{i=1}^{m} v_{i} x_{i j}} \leq 1 & ; \mathrm{j}=1,2, \ldots . . \mathrm{n} \\
\frac{u_{0}+u_{r}}{\sum_{i=1}^{m} v_{i} x_{i j}} \geq \varepsilon & ; \mathrm{r}=1,2, \ldots . \mathrm{s} \\
\frac{u_{0}+v_{i}}{\sum_{i=1}^{m} v_{i} x_{i j}} \geq \varepsilon & ; \mathrm{i}=1,2, \ldots . \mathrm{m} \\
u_{r}, v_{i} \geq \varepsilon \text { and } u_{0} \text { is unrestricted. } &
\end{array}
$$

Where $\varepsilon>0$ is the non-Archimedean infinitesimal number. The decision variables $u_{r}$ and $v_{i}$ are the weights. The $y_{r j}>0$ represents observed amounts of the $\mathrm{r}^{\text {th }}$ output $(\mathrm{r}=1,2, \ldots \mathrm{s})$ and the $x_{i j}>0$ represents observed amounts of the $i^{\text {th }}$ input $(i=1,2, \ldots . . m)$ for $j^{\text {th }}$ DMU denoted as $D_{M U} ; j=1,2, \ldots . n$.

The ratio DEA model measures the efficiency of DMUo as the maximum of the ratio of its weighted sum of outputs to weighted sum of inputs as $\quad e_{0}=\frac{u_{0}+\sum_{r=1}^{s} u_{r} y_{r 0}}{\sum_{i=1}^{m} v_{i} x_{i 0}}$ where the maximum is sought subject to

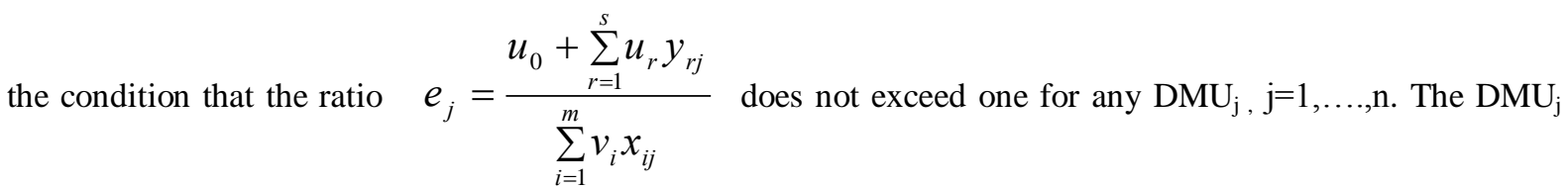
makes use of these m-inputs to produce s-outputs. One of the DMUs is placed in the objective function of M(1), denoted as $\mathrm{DMU}_{\mathrm{o}}$, which also consider in the constraints.

The problem in (M1) would be computationally difficult to resolve. Fortunately, theory of fractional programming, given in Charnes and Cooper [4], makes it possible to replace (M1) with an equivalent linear programming problem. The transformation to accomplish this can be found in Charnes, Cooper, and Rhodes [3]. We rewrite (M1) by using the results of the transformation [3] as

Maximise $u_{0}+\sum_{r=1}^{s} u_{r} y_{r o}$

Subject to:

$$
\begin{aligned}
& \sum_{i=1}^{m} v_{i} x_{i 0}=1 \\
& u_{0}+\sum_{r=1}^{s} \boldsymbol{u}_{r} y_{r j}-\sum_{i=1}^{m} v_{i} x_{i j} \leq 0 \quad ; \mathrm{j}=1,2, \ldots . . \mathrm{n} \\
& u_{r}, v_{i} \geq \varepsilon \text { and } u_{0} \text { is unrestricted }
\end{aligned}
$$

The constraint $\sum_{i=1}^{m} v_{i} x_{i 0}=1$ guarantees that it is possible to move from (M2) to (M1), as well as from (M1) to (M2). If the optimal value of the objective function is unit then $\mathrm{DMU}_{\mathrm{o}}$ is rated as relatively efficient, otherwise it is rated as relatively inefficient.

\section{Classical Transportation Problem:}

Suppose that m-warehouses contain various amounts of a homogeneous commodity which must be shifted to n-destinations. The $\mathrm{i}^{\text {th }}$ warehouse contain $a_{i}$ commodities $(\mathrm{i}=1,2, \ldots . \mathrm{m})$, while $\mathrm{j}^{\text {th }}$ destination requires $b_{j}$ commodities $(\mathrm{j}=1,2, \ldots \mathrm{n})$. We assume that the total available commodities equals to the total demand, 
$\sum_{i=1}^{m} a_{i}=\sum_{j=1}^{n} b_{j}$. There is cost $c_{i j}$ for shipping a unit commodity from warehouse i to destination $\mathrm{j}$. Let $x_{i j}$ be the number of units shipped from $i^{\text {th }}$ warehouse to $j^{\text {th }}$ destination. The problem is to determine a feasible shipping plan from warehouses to destinations which minimise total transportation cost.

We write transportation problem as the linear programming model as follows.

Minimise $\sum_{i=1}^{m} \sum_{j=1}^{n} c_{i j} x_{i j}$

Subject to :

$$
\begin{array}{ll}
\sum_{j=1}^{n} x_{i j}=a_{i} & ; \mathrm{i}=1,2, \ldots \ldots \mathrm{m} \\
\sum_{i=1}^{m} x_{i j}=b_{j} & ; \mathrm{j}=1,2, \ldots \ldots \mathrm{n}
\end{array}
$$

$x_{i j} \geq 0$, for all (i, j).

The simplex algorithm can be used to solve the forgoing transportation problem (Mokhtar S.Bazaraa et al. [8]).

\section{The Proposed Approach}

We extend a classical transportation problem by considering multiple incommensurate inputs and outputs for each shipping link. Consider m-warehouses with availability of $\boldsymbol{A}_{i}$ units of a commodity at ith warehouse. Consider n-destinations with requirements of $\boldsymbol{b}_{j}$ units of a commodity for jth destination. For each possible shipping link $(\mathrm{i}, \mathrm{j})$, the inputs and outputs are denoted as $X_{i j}=(\operatorname{xij}(1), \operatorname{xij}(2), \ldots \ldots . . x i j(s))$ and $Y_{i j}=(\mathrm{yij}(1), \mathrm{yij}(2), \ldots . . \mathrm{yij}(\mathrm{t}))$ respectively. For each shipment link $(\mathrm{i}, \mathrm{j})$, these are s+t attributes ,s- inputs $x_{i j}^{(k)}, \mathrm{k}=1,2, \ldots . \mathrm{s}$ and t-outputs $y_{i j}^{(l)}, 1=1,2, \ldots . \mathrm{t}$. We use the DEA technique to develop the solution procedure in such situation. For each warehouse $i$, we consider all destinations $j,(j=1,2, . . n)$ and each shipment link ( $i, j)$ as a DMU(1). By using (M2), we have relative efficiency of $i^{\text {th }}$ warehouse with shipment link $(i, j)$ as follows.

$$
e_{i j}^{(1)}=\operatorname{Max}\left\{u_{0}+\sum_{r=1}^{t} u_{r} y_{i j}^{(r)}\right\}
$$

Subject to :

$$
\begin{array}{ll}
\sum_{k=1}^{s} v_{k} x_{i j}^{(k)}=1 & \\
u_{0}+\sum_{r=1}^{t} u_{r} y_{i j}^{(r)}-\sum_{k=1}^{s} v_{k} x_{i j}^{(k)} \leq 0 & ; \mathrm{j}=1,2, \ldots \mathrm{n} \\
u_{r} \geq \varepsilon & ; \mathrm{r}=1,2, \ldots . \mathrm{t} \\
\boldsymbol{v}_{k} \geq \varepsilon & ; \mathrm{k}=1,2, \ldots . \mathrm{s} \\
\varepsilon>0 \text { and } \boldsymbol{u}_{0} \text { is unrestricted } & -
\end{array}
$$

Using (M4), we obtain the relative efficiency of $\mathrm{i}^{\text {th }}$ warehouse as $\mathrm{e}_{\mathrm{i} 1}{ }^{(1)}, \mathrm{e}_{\mathrm{i} 2}{ }^{(1)}, \ldots . . \mathrm{e}_{\mathrm{in}}{ }^{(1)}$ by changing the target warehouse in the model.

Meanwhile, for each destination $\mathrm{j}$, we consider all warehouses $\mathrm{i}(\mathrm{i}=1,2, \ldots \mathrm{m})$ and each possible link $(\mathrm{i}, \mathrm{j})$ as $\mathrm{DMU}^{(2)}$.With destination $\mathrm{j}$ as target, we have the relative efficiency of $\mathrm{j}^{\text {th }}$ destination with link $(\mathrm{i}, \mathrm{j})$ as follows.

$$
e_{i j}^{(2)}=\operatorname{Max}\left\{u_{0}+\sum_{r=1}^{t} u_{r} y_{i j}^{(r)}\right\}
$$

Subject to :

$$
\sum_{k=1}^{s} v_{k} x_{i j}^{(k)}=1
$$




$$
\begin{array}{lr}
u_{0}+\sum_{r=1}^{t} u_{r} y_{i j}^{(r)}-\sum_{k=1}^{s} v_{k} x_{i j}^{(k)} \leq 0 & ; \mathrm{i}=1,2, \ldots \mathrm{m} \\
u_{r} \geq \varepsilon & ; \mathrm{r}=1,2, \ldots . \mathrm{t} \\
v_{k} \geq \varepsilon & ; \mathrm{k}=1,2, \ldots . \mathrm{s} \\
\varepsilon>0 \text { and } u_{0} \text { is unrestricted. } &
\end{array}
$$

Using (M5), we get the relative efficiency of $\mathrm{j}^{\text {th }}$ destination to each warehouse as $\mathrm{e}_{1 \mathrm{j}}{ }^{(2)}, \mathrm{e}_{2 \mathrm{j}}{ }^{(2)}, \ldots . . . \mathrm{e}_{\mathrm{mj}}{ }^{(2)}$ by changing the target destination in the model.

We have determined the relative efficiency of any warehouse to each destination based on the set of decision making units (DMUs ${ }^{(1)}$ ). Similar process is undertaken for each warehouse. The two groups of relative efficiencies are obtained for the comparisons from either the warehouse side or the destinations side. For the transportation problem with multiple inputs and outputs, we need to optimise the total efficiency for entire shipment. We therefore construct a composite efficiency index to incorporate the two kinds of relative efficiencies as follows.

$$
e_{i j}=\frac{e_{i j}^{(1)}+e_{i j}^{(2)}}{2} ; \mathrm{i}=1,2, \ldots . . \mathrm{m} ; \mathrm{j}=1,2, \ldots \ldots . \mathrm{n} .
$$

We consider the values of the composite efficiency index as performance measure of shipment link ( $i, j)$. We also defined a performance measure of shipment link $(\mathrm{i}, \mathrm{j}$ ) by considering most efficient DMUs as follows.

$$
e_{i j}^{*}=\operatorname{Max}\left\{e_{i j}^{(1)}, e_{i j}^{(2)}\right\} ; \text { for each shipment link (i, j). }
$$

We decide the transportation plan by solving two separate models as,

$$
\text { Minimise } \sum_{i=1}^{m} \sum_{j=1}^{n}\left(1-e_{i j}\right) x_{i j}
$$

Subject to:

$$
\begin{array}{ll}
\sum_{j=1}^{n} x_{i j}=a_{i} & ; \mathrm{i}=1,2, \ldots . . \mathrm{m} \\
\sum_{i=1}^{m} x_{i j}=b_{j} & ; \mathrm{j}=1,2, \ldots \ldots \mathrm{n} \\
x_{i j} \geq 0 \quad ; \text { for all }(\mathrm{i}, \mathrm{j}) . & \text {--------- (M8) } \\
\text { and the another model as, } & \\
\text { Minimise } \sum_{i=1}^{m} \sum_{j=1}^{n}\left(1-e_{i j}\right) x_{i j} &
\end{array}
$$

Subject to :

$$
\begin{array}{lc}
\sum_{j=1}^{n} x_{i j}=a_{i} & ; \mathrm{i}=1,2, \ldots \ldots . \mathrm{m} \\
\sum_{i=1}^{m} x_{i j}=b_{j} & ; \mathrm{j}=1,2, \ldots \ldots, \mathrm{n} \\
x_{i j} \geq 0 & ; \text { for all }(\mathrm{i}, \mathrm{j}) .
\end{array}
$$
algorithm.

The forgoing problems are classical transportation problems and can be solved by using simplex

\section{Numerical Example}

Suppose a company produces auto-taxi at various plants viz. A, B, C, D and E. The production is send to three major cities viz. F, G and $\mathrm{H}$. The company manager considers one input (shipping cost) and two outputs (the value of shipment and profit). The appropriate input-output, availabilities $\left(a_{i}\right)$ and requirements $\left(b_{j}\right)$ are listed in [Table-1]. Each ordered triplet $\left(\mathrm{x}_{1}, \mathrm{y}_{1}, \mathrm{y}_{2}\right)$ shows (shipping cost, value of shipment, profit).

By using models (M4) and (M5), the efficiencies for the set of DMUs ${ }^{(1)}$ and DMUs ${ }^{(2)}$ are obtained by using the data as given in [ Table-1]. The calculated efficiencies are given in [ Table-2]. Each cell in [Table-2] shows two efficiency values for DMUs ${ }^{(1)}$ and DMUs ${ }^{(2)}$ respectively. We determined composite efficiency index $\left(\mathrm{e}_{\mathrm{ij}}\right)$ by using (M6) and are given in [Table-3]. The transportation plan with maximum 
efficiency is decided by solving the model (M8) for the data given in [Table-3]. The optimal solution obtained is as follows.

$$
X_{\mathrm{AG}}=10, \quad \mathrm{X}_{\mathrm{AH}}=20, \quad \mathrm{X}_{\mathrm{BF}}=15, \quad \mathrm{X}_{\mathrm{CG}}=25, \quad \mathrm{X}_{\mathrm{DF}}=18, \quad \mathrm{X}_{\mathrm{EF}}=2, \quad \mathrm{X}_{\mathrm{EG}}=10 .
$$

The objective value of model (M8) is 5.476 with the maximum efficiency is of $\mathbf{9 4 . 5 2 4}$.

Similarly, we obtain efficiency index $\left(e_{i j}^{*}\right)$ by using (M7) and are given in [Table-4]. The transportation plan with maximum efficiency is obtained by solving the model (M9) for the data in [Table-4]. The optimal solution obtained is as follows.

$$
\mathrm{X}_{\mathrm{AG}}=30, \quad \mathrm{X}_{\mathrm{BF}}=15, \quad \mathrm{X}_{\mathrm{CF}}=20, \quad \mathrm{X}_{\mathrm{CG}}=5, \quad \mathrm{X}_{\mathrm{DH}}=18, \quad \mathrm{X}_{\mathrm{EG}}=10, \quad \mathrm{X}_{\mathrm{EH}}=2 \text {. }
$$

The objective value of model (M9) is zero with efficiency is of $\mathbf{1 0 0 .}$

By using Alireza Amirteimoori [1] CCR approach, we determined the efficiency values to each shipment link ( $\mathrm{i}, \mathrm{j}$ ) to our example and are given in [Table-6]. The simplex method is used to solve the transportation problem (M8) for the data in [Table-6]. The optimal solution obtained is as follows.

$$
X_{\mathrm{AG}}=10, \quad X_{\mathrm{AH}}=20, \quad \mathrm{X}_{\mathrm{BG}}=15, \quad \mathrm{X}_{\mathrm{CF}}=17, \quad \mathrm{X}_{\mathrm{CG}}=8, \quad \mathrm{X}_{\mathrm{DF}}=18, \quad \mathrm{X}_{\mathrm{EG}}=12 \text {. }
$$

The objective value of model (M8) by Alireza Amirteimoori [1] CCR approach is 14.6702 with maximum efficiency is $\mathbf{8 5 . 3 3 2 4}$.

Similarly, we solve the model (M7) using data in [Table-5] and efficiency index $\left(e_{i j}^{*}\right)$ to each possible link $(i, j)$ are given in [Table-7]. The transportation plan with maximum efficiency is decided by solving the model (M9) for the data in [Table-7]. The optimal solution obtained is as follows.

$$
\mathrm{X}_{\mathrm{AG}}=25, \quad \mathrm{X}_{\mathrm{AH}}=5, \quad \mathrm{X}_{\mathrm{BH}}=15, \quad \mathrm{X}_{\mathrm{CF}}=17, \quad \mathrm{X}_{\mathrm{CG}}=8, \quad \mathrm{X}_{\mathrm{DF}}=18, \quad \mathrm{X}_{\mathrm{EG}}=12 \text {. }
$$

The objective value of model (M9) by Alireza Amirteimoori [1] CCR approach is 1.5709 with maximum efficiency is $\mathbf{9 8 . 4 2 9 1}$.

We compare the value of objective functions (M8) and $M(9)$ of our proposed approach with the approach suggested by Alireza Amirteimoori [1]. We have seen that our proposed approach provides more efficient solution than the approach suggested by Alireza Amirteimoori [1].

\section{Conclusion}

This paper extended the classical transportation problem by involving multiple inputs and multiple flexible outputs to each shipment link. The proposed approach is DEA-based considering BCC model on the relative efficiency of each possible link as a measure of performance to decide a transportation plan with maximum efficiency. The proposed approach is useful when the decision maker has multiple goals to achieve for each possible shipment link and these goals may be in conflict to each other. An illustrative numerical example is considered to show the applicability of the said approach to real life situation. In this example, we have seen that our proposed approach provides more efficient solution than the approach suggested by Alireza Amirteimoori [1] by using CCR based model for transportation problem. So, we suggest to employ proposed approach to solve transportation problem with multiple inputs and multiple flexible outputs.

Table-1: Transportation problem

\begin{tabular}{|c|c|c|c|c|}
\hline \multirow{2}{*}{ Places } & \multicolumn{3}{|c|}{ Major Cities } & $\mathrm{a}_{\mathrm{i}}$ \\
\cline { 2 - 5 } & $\mathrm{F}$ & $\mathrm{G}$ & $\mathrm{H}$ & \\
\hline $\mathrm{A}$ & $(9,95,270)$ & $(9,84,363)$ & $(7,97,288)$ & 30 \\
\hline $\mathrm{B}$ & $(8,93,492)$ & $(6,98,473)$ & $(5,85,478)$ & 15 \\
\hline $\mathrm{C}$ & $(6,83,319)$ & $(10,99,460)$ & $(9,82,348)$ & 25 \\
\hline $\mathrm{D}$ & $(5,85,426)$ & $(10,87,353)$ & $(7,99,490)$ & 18 \\
\hline $\mathrm{E}$ & $(6,98,395)$ & $(4,90,485)$ & $(3,75,395)$ & 12 \\
\hline $\mathrm{b}_{\mathrm{j}}$ & 35 & 45 & 20 & \\
\hline
\end{tabular}

Table-2: Efficiencies for the set of

\begin{tabular}{|c|c|c|c|}
\hline \multirow{2}{*}{ Places } & \multicolumn{3}{|c|}{ Major Cities } \\
\cline { 2 - 4 } & $\mathrm{F}$ & $\mathrm{G}$ & $\mathrm{H}$ \\
\hline \multirow{3}{*}{$\mathrm{A}$} & .7778 & 1 & .7778 \\
.641 & .4444 & .9524 \\
\hline & 1 & 1 & 1 \\
$\mathrm{~B}$ & 1 & 1 & 1 \\
\hline & 1 & 1 & .7581 \\
$\mathrm{C}$ & .8333 & 1 & .4629 \\
\hline & 1 & .5286 & 1 \\
$\mathrm{D}$ & 1 & .4 & 1 \\
\hline & 1 & 1 & 1 \\
$\mathrm{E}$ & 1 & 1 & 1 \\
\hline
\end{tabular}


Table-3: Composite efficiency index DMUs ${ }^{(1)}$ and DMUs ${ }^{(2)}$. $\left(\mathrm{e}_{\mathrm{ij}}\right)$ of proposed approach .

\begin{tabular}{|l|l|l|l|}
\hline \multirow{2}{*}{ Places } & \multicolumn{3}{|l|}{ Major Cities } \\
\cline { 2 - 4 } & $\mathrm{F}$ & $\mathrm{G}$ & $\mathrm{H}$ \\
\hline $\mathrm{A}$ & .7094 & .7222 & .8651 \\
\hline $\mathrm{B}$ & 1 & 1 & 1 \\
\hline C & .9166 & 1 & .6105 \\
\hline $\mathrm{D}$ & 1 & .4643 & 1 \\
\hline E & 1 & 1 & 1 \\
\hline
\end{tabular}

Table-4: Efficiency values $\left(e_{i j}^{*}\right)$ of proposed approach.

\begin{tabular}{|l|l|l|l|}
\hline \multirow{2}{*}{ Places } & \multicolumn{4}{|l|}{ Major Cities } \\
\cline { 2 - 4 } & F & G & H \\
\hline A & .7778 & 1 & .9524 \\
\hline B & 1 & 1 & 1 \\
\hline C & 1 & 1 & .7581 \\
\hline D & 1 & .5286 & 1 \\
\hline E & 1 & 1 & 1 \\
\hline
\end{tabular}

Table-5: Efficiencies by using CCR model (AlirezaAmirteimoori[1])approach for the set of DMUs ${ }^{(1)}$ and DMUs $^{(2)}$.

\begin{tabular}{|c|c|c|c|}
\hline \multirow{2}{*}{ Places } & \multicolumn{3}{|c|}{ Major Cities } \\
\cline { 2 - 4 } & $\mathrm{F}$ & $\mathrm{G}$ & $\mathrm{H}$ \\
\hline $\mathrm{A}$ & .7617 & .9803 & 1 \\
& .6209 & .4148 & .5543 \\
\hline & .6838 & .9608 & 1 \\
$\mathrm{~B}$ & .7218 & .7259 & .7261 \\
\hline & 1 & .8652 & .7273 \\
$\mathrm{C}$ & .8137 & .44 & .3644 \\
\hline & 1 & .5118 & .8319 \\
$\mathrm{D}$ & 1 & .3867 & .5657 \\
\hline & .6533 & .9209 & 1 \\
$\mathrm{E}$ & .9608 & 1 & 1 \\
\hline
\end{tabular}

Table-6: Composite efficiency index $\left(e_{\mathrm{ij}}\right)$ by Alireza Amirteimoori[1] approach.

\begin{tabular}{|c|c|c|c|}
\hline \multirow{2}{*}{ Places } & \multicolumn{3}{|c|}{ Major Cities } \\
\cline { 2 - 4 } & $\mathrm{F}$ & $\mathrm{G}$ & $\mathrm{H}$ \\
\hline $\mathrm{A}$ & .6913 & .6975 & .7772 \\
\hline $\mathrm{B}$ & .7028 & .8434 & .8631 \\
\hline $\mathrm{C}$ & .9069 & .6526 & .5456 \\
\hline $\mathrm{D}$ & 1 & .4493 & .6988 \\
\hline $\mathrm{E}$ & .8071 & .9605 & 1 \\
\hline
\end{tabular}

Table-7: Efficiency values $\left(e_{i j}^{*}\right)$ by AlirezaAmirteimoori[1] approach.

\begin{tabular}{|c|c|c|c|}
\hline \multirow{2}{*}{ Places } & \multicolumn{3}{|c|}{ Major Cities } \\
\cline { 2 - 4 } & $\mathrm{F}$ & $\mathrm{G}$ & $\mathrm{H}$ \\
\hline $\mathrm{A}$ & .7617 & .9803 & 1 \\
\hline $\mathrm{B}$ & .7218 & .9608 & 1 \\
\hline $\mathrm{C}$ & 1 & .8652 & .7273 \\
\hline $\mathrm{D}$ & 1 & .5118 & .8319 \\
\hline $\mathrm{E}$ & .9608 & 1 & 1 \\
\hline
\end{tabular}

\section{References}

[1]. Alireza Amirteimoori (2012):An extended transportation problem: a DEA -based approach.: Central European Journal of Operations research 19:513-521.

[2]. Banker R.D., Charnes A., Cooper W.W.(1984):Some methods for estimating technical and scale inefficiencies in data envelopment analysis. Management Sci.30(9):1078-1092.

[3]. Charnes A., Cooper W.W., Rhodes E.(1978):Measuring the efficiency of decision making units. European Journal of Operational Research 2(6):429-444.

[4]. Charnes A.,Cooper W.W.(1962):Programming with linear fractional functions. Naval Research Logistic quarterly 9:181-186.

[5]. Chen L.H., Lu H.W(2007):An extended assignment problem considering multiple inputs and outputs. Applied Mathematical modelling31:2239-2248.

[6]. Cooper W. W., Seriford L.M., Tone K(2007):Data envelopment analysis: a comprehensive text with models, applications, references and DEA-solver software. $2^{\text {nd }}$ edn. Springer. Berlin.

[7]. Cooper W. W., Seriford L.M., Zhu J(2004):Handbook of data envelopment analysis. Kluwer Academic Publishers. Norwell.

[8]. Mokhtar S. Bazaraa ,Johon J. Jarvis , Hanif D. Shevali (2011):Linear programming and network flows. $3^{\text {rd }}$ edn. Willey, New York. 